\title{
A 14 Years Hospital Based Study on Clinical and Morphological Spectrum of Hydatid Disease
}

\author{
Dilasma Ghartimagar, ${ }^{1}$ Arnab Ghosh, ${ }^{1}$ Manish Kiran Shrestha, ${ }^{2}$ OP Talwar, ${ }^{1}$ Brijesh Sathian ${ }^{3}$ \\ 'Department of Pathology, Manipal College of Medical Sciences, ${ }^{2}$ Department of Radiology, Gandaki Medical College, \\ ${ }^{3}$ Department of Community Medicine, Manipal College of Medical Sciences, Pokhara, Kaski, Nepal.
}

\section{ABSTRACT}

Introduction: Hydatid disease is endemic in sheep and cattle-raising areas worldwide. Its prevalence is high in Nepal. The study was carried out to determine the clinical, radiological and pathological presentations of hydatid disease.

Methods: This was a retrospective study of all hydatid disease cases reported in Department of Pathology, from August 1996 to July 2010. All the clinical, radiological and pathological data were collected and collated.

Results: A total of 51 cases of hydatidosis were studied. Patients presented with related symptoms in 47 cases, $92.16 \%$ with CI $(84.78,99.54)$ and asymptomatic in four cases, $7.84 \%$ with CI $(0.46,15.22)$. Involvement of liver and lung was found in 35 (68.63\%) cases and 10 (19.61\%) cases respectively. Involvement of other organs like kidney, pelvis and broad ligament were seen in 6 of the cases. Total 29 cases, $56.86 \%$ with CI $(43.2,70.46)$ had solitary cyst while rest of the cases had multiloculated cyst. All cases had radiological correlation and histopathological confirmation.

Conclusions: Most cases presented with organ related vague symptoms, however it should be considered as a differential diagnosis especially in asymptomatic cases and cases with unusual sites. Imaging studies is useful in preoperative diagnosis and postoperative histopathology is confirmatory. A multicentric hospital based study will help to decrease the incidence.

Keywords: echinoccocus; hydatid cyst; hydatidosis.

\section{INTRODUCTION}

Hydatidosis is one of the most wide spread helminth zoonotic disease in humans. ${ }^{1}$ Although effective preventive and therapeutic measures have been developed, it still remains an important public health problem in many parts of the world. ${ }^{2-4}$ The annual incidence rates of hydatid disease ranges from 1 to 220 cases per 100,000 in endemic areas..$^{2,5}$

Hydatid disease is caused by the larval stage of the tapeworm of genus Echinococcus. Like any other cystodes, it has both definitive and intermediate hosts. The definitive hosts are canines and the intermediate hosts are sheep, cattle and humans. ${ }^{3}$ Ingestion of eggs by susceptible intermediate hosts result in release of an early stage larva in the intestine which can migrate through blood or lymph to different organs like liver and lung where it grows into a cyst called hydatid cyst. ${ }^{6,7}$ In the present study, we try to analyze the data of echinococcosis in our hospital.

Correspondence: Dr. Dilasma Ghartimagar, Department of Pathology, Manipal Medical College, Pokhara, Nepal. Email: dilasmagm@ hotmail.com, Phone: 9840603962 


\section{METHODS}

It was a retrospective study carried out over a period of 14 years (August 1996 to July 2010) in the Departments of Pathology and Radiology. All the cases diagnosed as hydatid disease in the same period were included in the study. The details of all the cases regarding their demographic parameters, routine hematological findings, clinical presentations, impressions of radiological imaging and histopathology were retrieved, reviewed and analyzed. The radiological imaging included chest X-rays (CXR), Ultrasonography (USG) and CT scan. The biopsy tissues were fixed in $10 \%$ formalin, processed routinely, embedded in paraffin and were stained with hematoxylin and eosin. The data collected was analyzed using descriptive statistics and Confidence Interval (CI) with Statistical Package for the Social Sciences (SPSS) for Windows Version 16.0 (SPSS Inc; Chicago, IL, USA) and EPI Info 3.5.1 Windows Version.Permission was taken from the hospital director to obtain and analyze the data.

\section{RESULTS}

There were a total of 51 cases of hydatid cyst reported in the Department of Pathology. The age of the patients with hydatid disease ranged from 5 to 75 years. The incidence was seen to peak at the age range of 21 30 years followed by increased incidence again in older people more than 40 years of age as shown in Table 1. The incidence of hydatid disease were more in female $36(70.59 \%)$ cases as compared to male $15(29.41 \%)$ cases. The female to male ratio is $2.4: 1$. The castewise distribution was shown below in Table 2 which depicts Gurung and Magars as the most affected caste $(41.18 \%)$ followed by Chhetris $(13.73 \%)$.

\begin{tabular}{|ccc|}
\hline \multicolumn{3}{|c|}{ Table 1. Distribution of cases according to age. } \\
\hline $\begin{array}{c}\text { Age range } \\
\text { (years) }\end{array}$ & $\begin{array}{c}\text { Number of cases, } \\
\text { Percentage } \\
(n=51)\end{array}$ & $\mathrm{Cl}$ \\
$0-10$ & $3(5.88 \%)$ & $(0,12.34)$ \\
$11-20$ & $8(15.69 \%)$ & $(5.71,25.67)$ \\
$21-30$ & $12(23.53 \%)$ & $(11.89,35.17)$ \\
$31-40$ & $4(7.84 \%)$ & $(0.46,15.22)$ \\
$41-50$ & $7(13.73 \%)$ & $(4.28,23.17)$ \\
$51-60$ & $9(17.65 \%)$ & $(7.18,28.11)$ \\
$61-70$ & $5(9.80 \%)$ & $(1.64,17.97)$ \\
$71-80$ & $3(5.88 \%)$ & $(0,12.34)$ \\
\hline
\end{tabular}

\begin{tabular}{|ccc|}
\hline $\begin{array}{c}\text { Table 2. Distribution of cases according to Ethnicity. } \\
\text { Ethnicity }\end{array}$ & $\begin{array}{c}\text { No of cases, } \\
\text { Percentage } \\
(n=51)\end{array}$ & $\mathrm{Cl}$ \\
Gurung & $11(21.57 \%)$ & $(10.28,32.86)$ \\
Magar & $10(19.61 \%)$ & $(8.71,30.50)$ \\
Chettri & $7(13.73 \%)$ & $(4.28,23.17)$ \\
Brahmin & $3(5.88 \%)$ & $(0,12.34)$ \\
Newar & $3(5.88 \%)$ & $(0,12.34)$ \\
Others & $17(33.33 \%)$ & $(20.40,46.27)$ \\
\hline
\end{tabular}

\section{Hematological Parameters}

All patients were tested for routine hematological parameters including Complete Blood Count, Peripheral Smear and Erythrocytic Sedimentation Rate. Only two cases showed eosinophilia while the rest findings were within normal limits. Any serological or immunological tests related to hydatidosis were not available in our set up.

\section{Site}

The distribution of all cases according to different site is shown in Table 3. Liver was the commonest site involving $35(68.63 \%)$ cases followed by lung $10(19.61 \%)$ cases. Other sites involved were kidney, pelvis, neck muscle, broad ligament and brain. In liver, majority was in right lobe $30(85.71 \%)$ cases of all liver hydatidosis while four cases showed involvement of both hepatic lobes. In lung, two cases showed bilateral involvement.

\begin{tabular}{|lcc|}
\hline \multicolumn{3}{|c|}{ Table 3. Distribution of cases according to site. } \\
Organ involved & $\begin{array}{c}\text { No of cases, } \\
\text { Percentage } \\
(\mathbf{n}=\mathbf{5 1})\end{array}$ & $\mathrm{Cl}$ \\
Liver & $\mathbf{3 5}(\mathbf{6 8 . 6 3 \% )}$ & $\mathbf{( 5 5 . 8 9 , 8 1 . 3 6 )}$ \\
Lung & $\mathbf{1 0}(\mathbf{1 9 . 6 1 \% )}$ & $\mathbf{( 8 . 7 1 , 3 0 . 5 0 )}$ \\
Other organs & $\mathbf{6 ( 1 1 . 7 6 \% )}$ & $(\mathbf{2 . 9 2 , 2 0 . 6 1 )}$ \\
i) Kidney & $2(3.92 \%)$ & $(0,9.25)$ \\
ii) Pelvic mass & $1(1.96 \%)$ & $(0,5.77)$ \\
iii) Broad ligament & $1(1.96 \%)$ & $(0,5.77)$ \\
iv) Neck muscle & $1(1.96 \%)$ & $(0,5.77)$ \\
v) Brain & $1(1.96 \%)$ & $(0,5.77)$ \\
\hline
\end{tabular}

\section{Clinical presentation}

Patients of hydatid disease show different clinical manifestations depending on site, size and organ involved. Among 35 cases of liver hydatidosis, 20 $(57.14 \%)$ cases presented with abdominal pain only, three $(8.57 \%)$ cases with abdominal lump 
only while five $(14.29 \%)$ cases presented with both abdominal pain as well as lump. Among the patients of lung hydatidosis ( $n=10$ ), half (five cases) had main complaints of breathlessness while remaining half had main complaints of cough, chest pain and hemoptysis.

\section{Radiological presentation}

On radiology, hydaid cyst was suspected and or given as a presumptive preoperative diagnosis in 50 (98.03\%) cases except one case which was a pelvic mass with a thick fibrous wall and was diagnosed as ovarian cyst on USG. Diagnosis of hydatid cyst in this case was given by histopathological examination. Among 35 cases of liver hydatidosis, 34 cases had USG and one case had CT scan of abdomen. Similarly among the lung hydatidosis (10 cases), six cases had chest X-ray while two cases had CT scan and USG each (Table 4). Among all the cases, $29(56.86 \%)$ cases in our study had solitary cyst while rest of the cases had multiloculated cyst.

\begin{tabular}{|llll|}
\hline $\begin{array}{l}\text { Table 4. Type of radiological imaging done in all } \\
\text { cases. }\end{array}$ \\
\hline \\
Liver $(\mathbf{n}=35)$ & X ray & USG & CT Scan \\
Lung $(\mathbf{n}=10)$ & 6 & 34 & 1 \\
Other organs $(\mathbf{n}=6)$ & - & 6 & 2 \\
\hline
\end{tabular}

\section{Pathology findings}

We had histopathological confirmation in all 51 cases. The gross examination of hydatid cyst varied from pearly white lamellated membranous structures to classical mother and daughter cyst filled with yellowish material. The cyst size varied from $0.6 \mathrm{~cm}$ to $19 \mathrm{~cm}$, mean size being $8.5 \mathrm{~cm}$. Microscopic examination of hydatid cyst mostly showed lamellated eosinophilic structures while a few cases showed classical 3 layers, brood capsules, hooklets and scolices.

Past history of hydatid cyst (diagnosed earlier before the study period) were found in three cases. We had follow up (one to three years) data of 15 cases including 11 liver and 4 lung hydatidoisis. Four cases with initial hepatic involvement had recurrence in liver.

\section{DISCUSSION}

Hydatid disease produced by Echinococcous granulosus remains an important sanitary problem in many regions of world. Moreover migrating current population from endemic areas is the reason why new cases of hydatid disease are being observed in areas with no previous prevalence where it can be considered a clinical entity. ${ }^{8}$

In the present study, a total of 51 cases were included.
Hydatidosis is related to presence of spherical primary cysts most commonly in liver $(60-65 \%)$ followed by lungs $(20 \%))^{3,5}$ In our study, liver involvement was seen in $35(68.63 \%)$ cases and pulmonary involvement was seen in $10(19.61 \%)$ cases. Right hepatic lobe is known to be involved more than in left lobe and $20 \%$ cases of hepatic hydatid disease may show more than one cyst in liver. ${ }^{9}$ Similarly, in the current study, majority showed right hepatic lobe involvement but involvement of both lobes, $11.43 \%$ (4/35) were less. Among pulmonary hydatid cases, $20 \%(2 / 10)$ had bilaterality similar to other data. ${ }^{10}$

Less usual sites include brain (1-2\%), heart/thorax $(2 \%)$, kidney $(2 \%)$, ureter $(<1 \%)$, spleen $(6 \%)$, uterus $(<1 \%)$, fallopian tube $(<1 \%)$, mesentery $(<1 \%)$, pancreas $(<1 \%)$, diaphragm $(<1 \%)$, and bones/muscles (4\%).5,6,11 In our study, we found 2 cases in kidney and one case each in broad ligament, pelvis, neck muscle and brain. In our study, females are more affected in a ratio of $2.4: 1$. In other studies, findings are variable with no definite gender predilection. ${ }^{12,13}$

Eosinophilia is uncommon unless there is rupture of the cyst. ${ }^{14}$ We had only two $(3.92 \%)$ cases with eosinophil count of more than $6 \%$. In the reports by Cavusoglu $\mathrm{H}$ et $\mathrm{al}^{15}$ Scherer $\mathrm{K}$ et $\mathrm{al}^{16}$ and Wani $\mathrm{I}$ et al, ${ }^{17}$ no eosinophilia was noted while in the study by Ghoshal AG et al, ${ }^{18} 7.5 \%$ cases showed eosinophilia. Other routine hematological parameters were normal in the present study as in other literature. ${ }^{16}$

Early diagnosis is important because prompt treatment results in reduced morbidity and mortality. In most cases, the initial diagnosis by clinical features alone is difficult. ${ }^{1}$ The clinical presentation of hydatid disease depends on the site and size of the lesion as well as accessibility of the organ involved for clinical examination. The early phase following infection is always asymptomatic and may remain so for months to years. It may turn symptomatic when the growing cyst exerts pressure on adjacent tissues / organs, following rupture of the cyst or if the cyst becomes super infected. Most cysts become symptomatic when it becomes $>5 \mathrm{~cm}$ but in lung, even very small cysts may produce symptoms. ${ }^{1}$ Most hepatic hydatid disease present as abdominal pain with or without hepatomegaly. ${ }^{3,5,19}$ In the present study, all hepatic cases presented with either pain and /or mass. However, vomiting, cholestatic jaundice and symptoms mimicking cholelithiasis are also reported. ${ }^{3,5}$

Pulmonary hydatid cysts usually produce cough, breathlessness, chest pain or hemoptysis similar to our study. ${ }^{3,19-21}$ In heart and brain it may be lethal while in other sites, the symptoms are mostly related to pressure effect. $^{5}$ 
Though histopathology is the gold standard and confirmatory for the diagnosis, imaging procedures especially together with serology often indicates the diagnosis of hydatid disease..$^{3,5}$ USG is the preoperative diagnostic procedure of choice. ${ }^{5}$ Hepatic hydatid cyst on USG present as a complex heterogenous mass, sometimes with various findings described as snow storm sign, racemose appearance, honey comb appearance, wheel spoke pattern and water lilly sign. ${ }^{9}$ In lung, characterstic features may be seen either on CXR or on USG and the radiological findings are described as meniscus sign, moon sign, combo sign, serpent sign, water lilly sign etc. ${ }^{10,22}$ However, the main differential diagnosis include benign congenital cyst. ${ }^{5}$ In a large series of pulmonary hydatid studied by Montazeri $V$ et al, the accuracy of CXR was $84 \%$ and $74 \%$ in children and adult respectively. ${ }^{22}$ An international classification system of USG images to diagnose hydatidosis has been elaborated for application in clinical and field settings. ${ }^{5,23}$ Based on USG, WHO proposed a morphological classification of hepatic cystic echinococcosis (CE) and divided it into five groups, CE1-CE5, characterized by the appearance of the cysts contents and wall. ${ }^{1,23} \mathrm{CT}$ is advantageous because of its ability to explore any organ specially as lungs are not explored by USG. ${ }^{24}$ Among other imaging studies MRI is also useful as MRI has advantages over CT scan in evaluation of soft tissue and bony hydatid cyst. ${ }^{6}$ Echocardiography is useful in identifying cardiac lesions. ${ }^{24,25}$ USG is also helpful in monitoring the response of cyst to treatment. ${ }^{3,25}$

Immunodiagnostic tests for the detection of serum antibodies or circulating antigens are used to support the clinical or radiological diagnosis. ${ }^{5}$ Different serological tests are being carried out for the diagnosis which includes Enzyme-Linked ImmunoSorbent Assay (ELISA), latex agglutination and indirect haemagglutination (IHA) test. $^{26,27}$ However, negative serological result does not rule out hyadatid disease and is more common in lung than in liver involvement. ${ }^{3}$ Molecular study over hydatid cyst shows that Echinococcusgranulosus exhibits substantial genetic diversity that has important implications for the design and development of vaccines. DNA approaches like use of DNA probes are useful for the accurate identification of this genus. ${ }^{27}$

Gurungs and Magars constituted the largest group $(41.18 \%)$ in the current study. It may be related to dietary habit or may be due to the fact that they comprise the majority of the general population in the catchment area of the hospital. Further epidemiologic study on this issue is necessary for any definite conclusion.

At present the definitive treatment for hydatid cyst is surgical removal of the cyst which remains the gold standard. 3,28,29 Besides surgery, non conventional treatment like PAIR (Puncture, Aspiration, Injection, Reaspiration) had been widely studied recently and was found safe and effective. ${ }^{30}$ In medical treatment imidazole group of drugs (mebendazole and albendazole) are widely used but are contraindicated in pregnancy, hepatic and renal impairment. ${ }^{1}$

\section{CONCLUSIONS}

Our study showed that most cases presented with nonspecific symptoms which might make it difficult to diagnose clinically. Thus, radiology as in current study, plays a major role in preoperative diagnosis especially in unusually located and asymptomatic cases. Postoperative histopathological diagnosis is however confirmatory. This research is based on the hospital study from Western Development Region of Nepal. A multicentric hospital based study with higher sample size will be beneficial to find out the high risk groups and predisposing habits so that the incidence can be decreased.

\section{REFERENCES}

1. Siracusano A, Teggi A, Ortona E. Human cystic echinococcosis: old problems and new perspectives. InterdiscipPerspect Infect Dis. 2009:474368.

2. Mandell GL, Douglas RG, Bennett JE, Dolin R, editors. Mandell, Douglas and Bennett's principles and practice of infectious diseases. 5th ed. Philadelphia: Churchill Livingstone; 2000. p. 2956-65.

3. White AC Jr, Weller PF. Cestodes. In: Fauci AS, Braunwald E, Kasper DL, Hauser SL, Longo DL, Jameson JL,editors. Harrison's Internal Medicine. 17th ed. McGraw Hill Companies; 2008. (vol 1). p.1338-40.
4. King C. Cestodes (tapeworms). In: Mandell G, Bennett J, Dolin R, editors. Principles and practices of infectious diseases. 5th ed. New York: Churchill Livingstone; 2000. p. 633-40.

5. Gottstein B, Reichen J. Echinococcosis/ Hydatidosis. In: Cook G, Zumla A, editors. Manson's Tropical Diseases. 21st ed. London: Elsevier Science, Health Sciences Division; 2003. p. 1561-77.

6. Kak VK, Mathuriya SN. Hydatid disease of the nervous system. In: Chopra JS, Sawhney BI, editors. Neurology in tropics. London: Churchill Livingstone; 1999. p. 244-58. 
7. Gabriele F, Bortoletti G, Conchedda M, Palmas C, Ecca AR. Epidemiology of hydatid disease in the Mediterranean basin with special reference to Italy. Parassitologia. 1997;39(1):47-52.

8. Ito A, Okamoto M, Ishiguro T, Ma L, Suzuki H, Yasui A. Short report: an imported case of cystic echinococcosis in Japan diagnosed by imaging and serology with confirmation of echinococcusgranulosus-specific DNA sequences. Am J Trop Med Hyg. 1998;58(6):790-2.

9. Dahnert W. Radiology Review Manual. 6th ed. New York: Lippincott Williams and Wilkins; 2007. p. 710-2.

10. Dahnert W. Radiology Review Manual. 6th ed. New York: Lippincott Williams and Wilkins; 2007. p. 500-1.

11. Chatterjee KD. Parasitology. 12 Ed. Calcutta: Chatterjee Medical Publishers. p. 107-32.

12. Aribas OK, Kanat F, Gormus N, Turk E. Pleural complications of hydatid disease. Thorac Cardiovasc Surg. 2002;123:492-7.

13. Ali M, Mahmood K, Khan P. Hydatid cysts of the brain. J Ayub Med Coll Abbottabad. 2009;21(3):21-3.

14. Burgos R, Varela A, Castedo E, Roda J, Montero CG, Serrano S. Pulmonary hydatidosis: surgical treatment and follow-up of 240 cases. Eur J Cardiothorac Surg. 1999;16:628-35.

15. Cavusoglu H, Tuncer C, Ozdilmac A, Aydin Y. Multiple intracranial hydatid cysts in a boy. Turkish Neurosurgery. 2009;19:203-7.

16. Scherer K, Gupta N, Caine WP, Panda M. Differential diagnosis and management of a recurrent hepatic cyst: a case report and review of literature. J Gen Intern Med. 2009;24(10):1161-5.

17. Wani I, Wani S, Baba A, Khanday Z, Bhat N, Shera A et al. Primary calcified hydatid of spleen: a case report. Internet J Med Update. 2010;5(2):68-70.

18. Ghoshal AG, Sarkar S, Saha K, Sarkar U, Kundu S, Chatterjee $S$ et al. Hydatid lung disease: an analysis of five years cumulative data from kolkata. J Assoc Physicians India. 2012;60:12-6.

19. Kir A, Baran E. Simultaneous operation for hydatid cyst of right lung and liver. Thorac Cardiovasc Surg. 1995;43(1):62-4.
20. Tora M, Atasalihib A, Altuntasa N, Sulua E, Senola T, Kirb A . Review of cases with cystic hydatid lung disease in a tertiary referral hospital located in an endemic region: a 10 years experience. Respiration. 2000;67:539-42.

21. Mood BS, Fazaeli A, Mokhtari S. Fifteen years experience with pulmonary hydatidosis in Zahedan, Iran. Iranian J Parasitol. 2007;2(4):7-11.

22. Montazeri V, Sokouti M, Rashidi MR. Comparison of pulmonary hydatid disease between children and adults. Tanaffos. 2007;6(1):13-8.

23. WHO Informal Working Group 1. International classification of ultrasound images in cystic echinococcosis for application in clinical and field epidemiological settings. ActaTropica. 2003;85:253-61.

24. Guntz M, Coppo B, Lorimier G, Cronier P. Hydatid cysts of the liver appearing late (10 to 22 years) after surgical treatment of pulmonary hydatidosis. Physiopathologic problems. J Chir (Paris). 1990;127(8-9):375-81.

25. Altinors N, Senveli E, Donmez T, Bavbek M, Kars Z, Sanl M. Management of problematic intracranial hydatid cysts. Infection. 1995;23(5):283-7.

26. Brown RA, Millar AJ, Steiner Z, Krige JE, Burkimsher D, Cywes S. Hydatid cyst of the pancreas a case report in child. Eur J Pediatric Surgery. 1995;5:121-4.

27. McManus DP, Thompson RC. Molecular epidemiology of cystic echinococcosis. Parasitology. 2003;127 Suppl:S37-51.

28. Kant S, Singh R, Bhatia RS, Sanjay. Unusual presentation of hydatid disease. The Internet J Pul Med. 2008;10(1).

29. Marwah S, Kamal H, Marwah N. Laparoscopic management of a large primary retroperitoneal hydatid cyst. Clin J Gastroenterol. 2010;3(4):230-2.

30. WHO Informal Working Group on Echinococcosis World Health Organization. Department of Epidemic and Pandemic Alert and Response. Puncture, Aspiration, Injection, Re-aspiration : an option for the treatment of cystic echinococcosis / WHO Informal Working Group on Echinocossosis. Geneva : World Health Organization. 2001 Jun. p. 40 